\title{
ÁCIDO GIBERÉLICO NO CRESCIMENTO INICIAL DE MUDAS DE PESSEGUEIRO
}

\author{
Gibberellic acid in the initial growth of peach seedling
}

\author{
Américo Wagner Júnior ${ }^{1}$, José Osmar da Costa e Silva², Carlos Eduardo Magalhães dos Santos ${ }^{3}$, \\ Leonardo Duarte Pimentel ${ }^{4}$, Jacson Rondinelli da Silva Negreiros ${ }^{5}$, Claudio Horst Bruckner ${ }^{6}$
}

\begin{abstract}
RESUMO
O emprego de certas práticas culturais são fundamentais para obtenção de mudas de qualidade, com reduzido período de formação. Realizou-se, este trabalho, em casa de vegetação, no Departamento de Fitotecnia da Universidade Federal de Viçosa, com o objetivo de avaliar o efeito de cinco concentrações de ácido giberélico $\left(\mathrm{GA}_{3}\right)\left(0 ; 50 ; 100 ; 150\right.$ e $\left.200 \mathrm{mg} \mathrm{L} \mathrm{L}^{-1}\right)$, no crescimento inicial do pessegueiro. O delineamento experimental utilizado foi em blocos casualizados, com quatro repetições, considerando-se como unidade experimental, os quatro recipientes plásticos contendo uma planta cada. Foram realizadas três aplicações de $\mathrm{GA}_{3}(60,80 \mathrm{e}$ 100 dias de cultivo). Nas aplicações, a parte aérea foi molhada inteiramente, utilizando-se $20 \mathrm{ml}$ de solução para cada planta. Aos 130 dias da semeadura, foram analisados: comprimento da parte aérea e da raiz; diâmetro do caule; número de brotações primárias; massa da matéria seca da parte aérea e da raiz. Concluiu-se que o ácido giberélico exerceu efeito sobre o crescimento de pessegueiro, recomendando-se a pulverização de $200 \mathrm{mg} \mathrm{L}^{-1}$. As pulverizações de $\mathrm{GA}_{3}$ não tiveram efeito sobre o diâmetro do caule do pessegueiro.
\end{abstract}

Termos para indexação: Prunus persica, mudas, giberelina, propagação.

\section{ABSTRACT}

The use of some cultures practices are important for obtain quality seedlings with lowest time production. The work was carried out in a green house, at Viçosa Federal University, Plant Science Department, with the objective to evaluate the effect of five acid giberellic $\left(\mathrm{GA}_{3}\right)$ concentrations $\left(0 ; 50 ; 100 ; 150\right.$ e $\left.200 \mathrm{mg} \mathrm{L}^{-1}\right)$, on the initial growth of peach seedlings. The experiment was done as randomized blocks design, with four replications, where each plot constituted of four plastics recipients. Three GA 3 applications were realized (60, 80 and 100 cultivate days). The applications were done at the plants aerial part, using $20 \mathrm{ml}$ of solution for each plant. After 130 days of the sowing, the height and root length, diameter of the stem, number of primary ramifications of the aerial part and mass of the dry matter aerial part and of the dry root, were evaluated. It was concluded that the gibberellic acid application has influence on the growth of peach seedlings, manly the dose of $200 \mathrm{mg} \mathrm{L}^{-1}$. The GA application hasn't affect the stem diameter.

Index terms: Prunus persica, seedling, gibberellin, propagation.

(Recebido em 26 de abril de 2006 e aprovado em 14 de fevereiro de 2007)

\section{INTRODUÇÃO}

A produção brasileira de pêssegos, no ano de 2002, foi de 218.292 toneladas. Essa produção ainda é insuficiente para atender à demanda interna de frutos desta cultura. O Brasil importou neste mesmo ano, cerca de 3.980 e 7.031 toneladas de frutas destinadas ao mercado de frutas frescas e de pêssegos em calda, respectivamente (AGRIANUAL, 2005).

Assim, observa-se grande potencial de mercado em nosso país para essa cultura, uma vez que a produção nacional ainda não atingiu volume suficiente para atender à demanda interna.
O crescimento da persicultura em nosso país depende de muitos fatores e, dentre eles, destaca-se a utilização de mudas de qualidade, principalmente quanto aos aspectos sanitários e à correta identificação varietal.

Segundo Pasqual et al. (2001), a muda pode ser considerada como o alicerce da fruticultura, pois dela depende o sucesso ou fracasso da implantação de um pomar.

A propagação do pessegueiro (Prunus persica (L.) Batsch.), normalmente, é baseada na enxertia de cultivarescopa sobre porta-enxertos obtidos a partir de sementes (TOFANELLI et al., 2001). As sementes podem ser obtidas

\footnotetext{
Engenheiro Agrônomo, Doutor - Professor Adjunto - Departamento de Horticultura - Universidade Tecnológica Federal do Paraná - Campus Dois Vizinhos - Dois Vizinhos, PR - americowagner@utfpr.edu.br

${ }^{2}$ Engenheiro Agrônomo, Mestrando - Departamento de Fitotecnia - Universidade Federal de Viçosa/UFV - 36570-000 - Viçosa, MG joksilva7@yahoo.com.br. Bolsista CNPq

${ }^{3}$ Engenheiro Agrônomo, Doutor - Pós-Doutor em Fitotecnia - Departamento de Fitotecnia - Universidade Federal de Viçosa/UFV - $36570-000$ - Viçosa, MG - eduardomagsantos@yahoo.com.br - Bolsista FAPEMIG.

${ }^{4}$ Engenheiro Agrônomo, Doutor em Fitotecnia - Departamento de Fitotecnia - Universidade Federal de Viçosa/UFV - 36570-000 - Viçosa, MG agropimentel@yahoo.com.br - Bolsista CNPq.

${ }^{5}$ Engenheiro Agrônomo - Doutor - Pesquisador - Embrapa Acre - 69914-220 - Rio Branco, AC - jacson@cpafac.embrapa.br

${ }^{6}$ Engenheiro Agrônomo, Doutor - Professor Titular - Departamento de Fitotecnia -Universidade Federal de Viçosa/UFV - 36570-000 - Viçosa, MG - bruckner@ufv.br.
} 
junto às indústrias processadoras de pêssego, onde existe grande disponibilidade delas, como predomina no Sul do país, ou serem provenientes de cultivares selecionadas como porta-enxetos.

O emprego de práticas culturais como irrigação, adubação e controle de invasoras são fundamentais para obtenção de mudas de qualidade, além de poderem reduzir seu período de formação. O emprego de substâncias reguladoras de crescimento pode acelerar a taxa de crescimento das plantas (COELHO et al., 1983).

As giberelinas constituem uma das classes de reguladores de crescimento que têm efeito no controle do desenvolvimento vegetal (ALVARENGA, 1990). Segundo Taiz \& Zeiger (2004), as giberelinas, como o ácido giberélico $\left(\mathrm{GA}_{3}\right)$, aumentam a elongação e divisão celular, o que é evidenciado pelo aumento do comprimento e do número de células em resposta à aplicação deste fitorregulador.

Coelho et al. (1983) descrevem que o crescimento das plantas em altura deve-se à capacidade do $\mathrm{GA}_{3} \mathrm{em}$ estimular a expansão do caule. Para Ting (1982), esta expansão é consequiência da elongação das células e não do aumento na divisão celular.

Marth et al. (1965), estudando o efeito do $\mathrm{GA}_{3}$ em plantas de 49 espécies concluíram que as melhores respostas foram relacionadas ao aumento no crescimento do caule.

Porém, de acordo com Ramos (1980), o efeito do $\mathrm{GA}_{3}$ é variável de acordo com a concentração utilizada, número de aplicações e da espécie ou cultivar tratada.

O objetivo deste trabalho foi de avaliar os efeitos de doses do ácido giberélico, no crescimento inicial de plantas de pessegueiro.

\section{MATERIAL E MÉTODOS}

O trabalho foi realizado no Setor de Fruticultura, Departamento de Fitotecnia, da Universidade Federal de Viçosa, Viçosa-MG, de maio a setembro de 2005.

Os frutos de pessegueiro, obtidos por polinização livre, do cultivar 'Campinas-1', foram coletados maturos na Fazenda Experimental de Araponga, localizada no município de Araponga (MG), em dezembro de 2004, sendo os mesmos imediatamente despolpados e as sementes extraídas do endocarpo. Elas foram estratificadas em câmara fria utilizando-se temperatura constante de $5^{\circ} \mathrm{C}$, com ausência de luz. Todas as sementes foram estratificadas durante 40 dias.

Com o início da germinação, retirou-se o material da câmara fria e no interior da casa de vegetação procedeuse à semeadura a $1,0 \mathrm{~cm}$ de profundidade, em recipiente plástico (1 litro $-21 \mathrm{~cm} \times 14,5 \mathrm{~cm}$ ), contendo como substrato a mistura de Latossolo Vermelho + Plantmax ${ }^{\circledR}-3: 1 \mathrm{v} / \mathrm{v}$, enriquecido com $\mathrm{P}_{2} \mathrm{O}_{5}\left(3,0 \mathrm{~g} \mathrm{dm}^{-3}\right)$.

Após 60, 80 e 100 dias da semeadura, foram realizadas aplicações de ácido giberélico $\left(\mathrm{GA}_{3}\right)$, nas concentrações de $0 ; 50 ; 100 ; 150$ e $200 \mathrm{mg} \mathrm{L}^{-1}$, na parte aérea das plantas.

As concentrações de $\mathrm{GA}_{3}$ foram preparadas com o produto comercial Pro-Gibb ${ }^{\circledR}$, o qual contém $10 \%$ de $\mathrm{GA}_{3}$. Para preparação de cada solução, primeiramente, o $\mathrm{GA}_{3}$ foi diluído em álcool, sendo posteriormente acrescentada água destilada na mesma proporção, formando uma solução com volume de 1:1 v/v (álcool + água destilada). Assim, foram preparadas cinco soluções, diferindo somente na concentração de $\mathrm{GA}_{3}$.

As plantas foram molhadas inteiramente, utilizandose $20 \mathrm{~mL}$ de solução com $\mathrm{GA}_{3}$ para cada planta, com auxílio de um pulverizador manual, com capacidade de um litro de solução. A cada período de aplicação, foram feitas avaliações do comprimento da parte aérea $(\mathrm{cm})$ e do diâmetro do caule ( $\mathrm{mm})$.

Foi utilizado o delineamento experimental em blocos casualizados, com quatro repetições, considerando-se como unidade experimental os quatros recipientes plásticos, contendo uma planta cada.

Após 130 dias da semeadura, foram analisados: comprimento da parte aérea e da raiz $(\mathrm{cm})$; diâmetro do caule $(\mathrm{mm})$; número de brotações primárias; massa da matéria seca da parte aérea e da raiz das plantas $(\mathrm{g})$.

Os dados foram submetidos à análise de variância e ao teste de Tukey $(\alpha=0,05)$, sendo que o número de brotações primárias foram transformados previamente em $\sqrt{\mathrm{x}+1}$. Já os demais dados não sofreram transformação. Foi utilizado o aplicativo computacional SANEST (ZONTA \& MACHADO, 1984).

Para determinação do comprimento da parte aérea e da raiz das plantas, as mesmas foram retiradas dos substratos, cuidadosamente lavadas em água e medidas com auxílio de uma régua graduada em milímetros. Na obtenção dos dados de diâmetro do caule foi utilizado paquímetro digital graduado em milímetros, na altura do colo das plantas. O sistema radicular e a parte aérea foram secos em estufa de circulação forçada a $60^{\circ} \mathrm{C}$, até atingirem peso constante, obtido em 72 horas, para posterior determinação do valor da massa da matéria seca do sistema radicular e da parte aérea, sendo realizada a pesagem em balança analítica.

As temperaturas do ar, mínima e máxima foram obtidas, diariamente, no interior da casa de vegetação, sendo as médias de $18,55^{\circ} \mathrm{C}, 13,08^{\circ} \mathrm{C}$ e $26,84^{\circ} \mathrm{C}$, respectivamente. 


\section{RESULTADOS E DISCUSSÃO}

De acordo com a análise de variância, verificouse efeito significativo para o comprimento da parte aérea na interação dias de avaliação x concentração de $\mathrm{GA}_{3}$, sendo que aos 60 e 80 dias as concentrações de GA utilizadas, assemelharam-se estatisticamente entre si (Figura 1A).

Quanto ao diâmetro do caule, as retas lineares de desenvolvimento apresentaram comportamento semelhante nas cinco concentrações de $\mathrm{GA}_{3}$ aplicadas e na interação analisada, diferindo estatisticamente somente nos tempos de avaliação (Figura 1B).

Nas Figuras 1A e 1B, quando considerados os resultados obtidos em cada avaliação, em função das doses de $\mathrm{GA}_{3}$, verificou-se aumento linear significativo no comprimento da parte aérea e diâmetro do caule.

Observa-se, após a segunda aplicação, maior crescimento da parte aérea com o aumento das doses, sendo que o coeficiente angular aumentou com o aumento da dose de $\mathrm{GA}_{3}$, chegando a 0,5902 , na maior dose utilizada (200 $\mathrm{mg} \mathrm{L}^{-1}$ ) (Figura 1A).

Provavelmente, o maior crescimento foi consequiência do alongamento celular, o que refletiu no crescimento em altura, sem que fosse detectado aumento no diâmetro do caule comparando as doses aplicadas.

Os resultados da análise de variância, aos 130 dias de cultivo, nas concentrações de $\mathrm{GA}_{3}$ aplicadas mostraram que houve efeito significativo para o comprimento da parte aérea e massa da matéria seca da raiz (Figuras 2A e 2F). Já as demais variáveis analisadas apresentaram-se, estatisticamente, semelhantes (Figuras $2 \mathrm{~B}, 2 \mathrm{C}, 2 \mathrm{D}$ e $2 \mathrm{E}$ ).

Observa-se na Figura 2A comportamento linear crescente para o comprimento da parte aérea, podendo deste modo, comprovar que a aplicação de $\mathrm{GA}_{3}$ favoreceu o crescimento do caule do pessegueiro à medida que se aumentou a concentração deste fitorregulador.

De acordo com Sauter \& Kende (1992), esta resposta com maior crescimento inicial, é baseada na elongação das células do meristema intercalar, que ao aumentar de tamanho promovem a divisão celular. Com isso, as maiores taxas de crescimento são observadas pelo aumento na formação de novas células e pela maior elongação celular em resposta ao $\mathrm{GA}_{3}$.

Resultados semelhantes foram obtidos por Castro et al. (1991) com nogueira macadâmia, Leonel \& Rodrigues (1995) e Modesto et al. $(1994,1996)$ com limão 'Cravo', no qual verificaram incrementos no comprimento da parte aérea, com a elevação da concentração de $\mathrm{GA}_{3}$.

Por outro lado, com o aumento na concentração de $\mathrm{GA}_{3}$, houve redução na massa de matéria seca da raiz. Desse modo, pode-se observar que a principal ação benéfica da pulverização de $\mathrm{GA}_{3}$ sobre as plantas está relacionada com o desenvolvimento da parte aérea.

Modesto (1994) ressaltou que a principal ação exercida pela aplicação de giberelinas nas plantas está relacionada ao desenvolvimento da parte aérea das mesmas, especialmente no alongamento do caule.
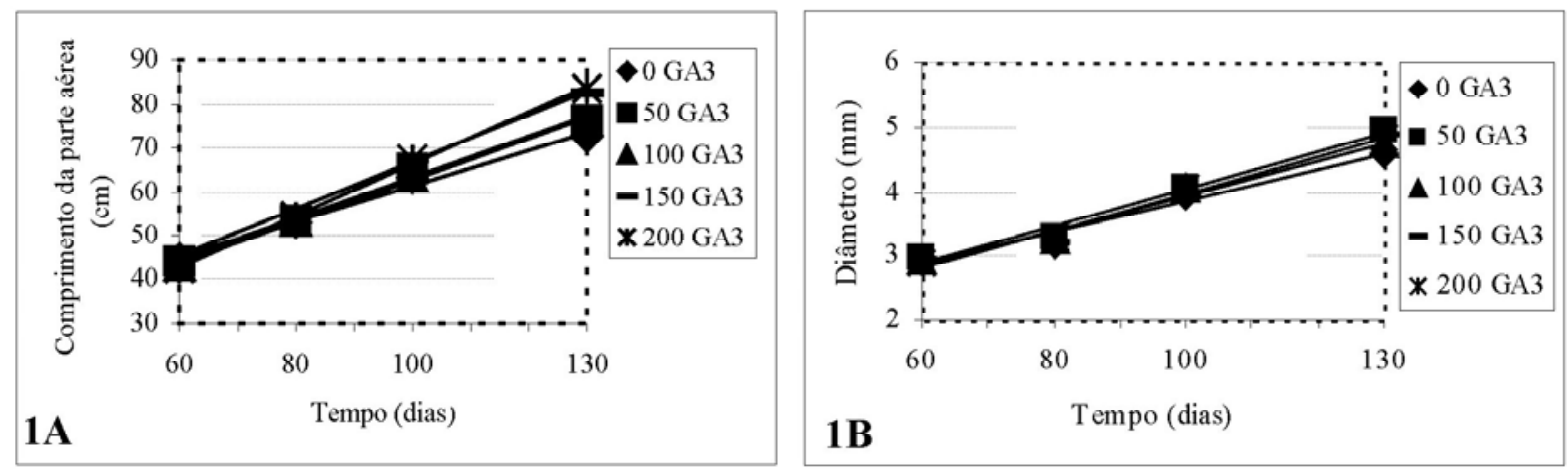

Figura 1 - Evolução do crescimento da parte aérea (A) e do diâmetro (B) dos pessegueiros em função das concentrações de $\mathrm{GA}_{3}\left(\mathrm{mg} \mathrm{L}^{-1}\right)$, nos quatro períodos de avaliação (60, 80, 100 e 130 dias após a semeadura).

Figura $1 \mathrm{~A}-0 \mathrm{mg} \mathrm{L}^{-1} \mathrm{de} \mathrm{GA}_{3}\left(\mathrm{Y}=0,4024 \mathrm{x}+21,112 / \mathrm{r}^{2}=0,9898\right) ; 50 \mathrm{mg} \mathrm{L}^{-1} \mathrm{de} \mathrm{GA}_{3}\left(\mathrm{Y}=0,4673 \mathrm{x}+16,526 / \mathrm{r}^{2}=0,9907\right) ; 100 \mathrm{mg} \mathrm{L} \mathrm{L}^{-1} \mathrm{de}$ $\mathrm{GA}_{3}\left(\mathrm{Y}=0,4745 \mathrm{x}+15,22 / \mathrm{r}^{2}=0,9974\right) ; 150 \mathrm{mg} \mathrm{L}^{-1} \mathrm{de} \mathrm{GA}_{3}\left(\mathrm{Y}=0,5379 \mathrm{x}+13,074 / \mathrm{r}^{2}=0,9993\right) ; 200 \mathrm{mg} \mathrm{L}^{-1} \mathrm{de} \mathrm{GA}_{3}(\mathrm{Y}=0,5902 \mathrm{x}$ $\left.+7,3493 / \mathrm{r}^{2}=0,9981\right)$.

Figura $1 \mathrm{~B}-0 \mathrm{mg} \mathrm{L}^{-1} \mathrm{de} \mathrm{GA}\left(\mathrm{Y}=0,0242 \mathrm{x}+1,4226 / \mathrm{r}^{2}=0,9731\right) ; 50 \mathrm{mg} \mathrm{L}^{-1} \mathrm{de} \mathrm{GA}\left(\mathrm{Y}=0,0292 \mathrm{x}+1,1194 / \mathrm{r}^{2}=0,9854\right) ; 100 \mathrm{mg} \mathrm{L}^{-1} \mathrm{de}$ $\mathrm{GA}_{3}\left(\mathrm{Y}=0,0269 \mathrm{x}+1,2502 / \mathrm{r}^{2}=0,9778\right) ; 150 \mathrm{mg} \mathrm{L}^{-1} \mathrm{de} \mathrm{GA}_{3}\left(\mathrm{Y}=0,0288 \mathrm{x}+1,0875 / \mathrm{r}^{2}=0,9838\right) ; 200 \mathrm{mg} \mathrm{L}^{-1} \mathrm{de} \mathrm{GA}_{3}(\mathrm{Y}=0,0285 \mathrm{x}$ $\left.+1,1149 / \mathrm{r}^{2}=0,9908\right)$. 

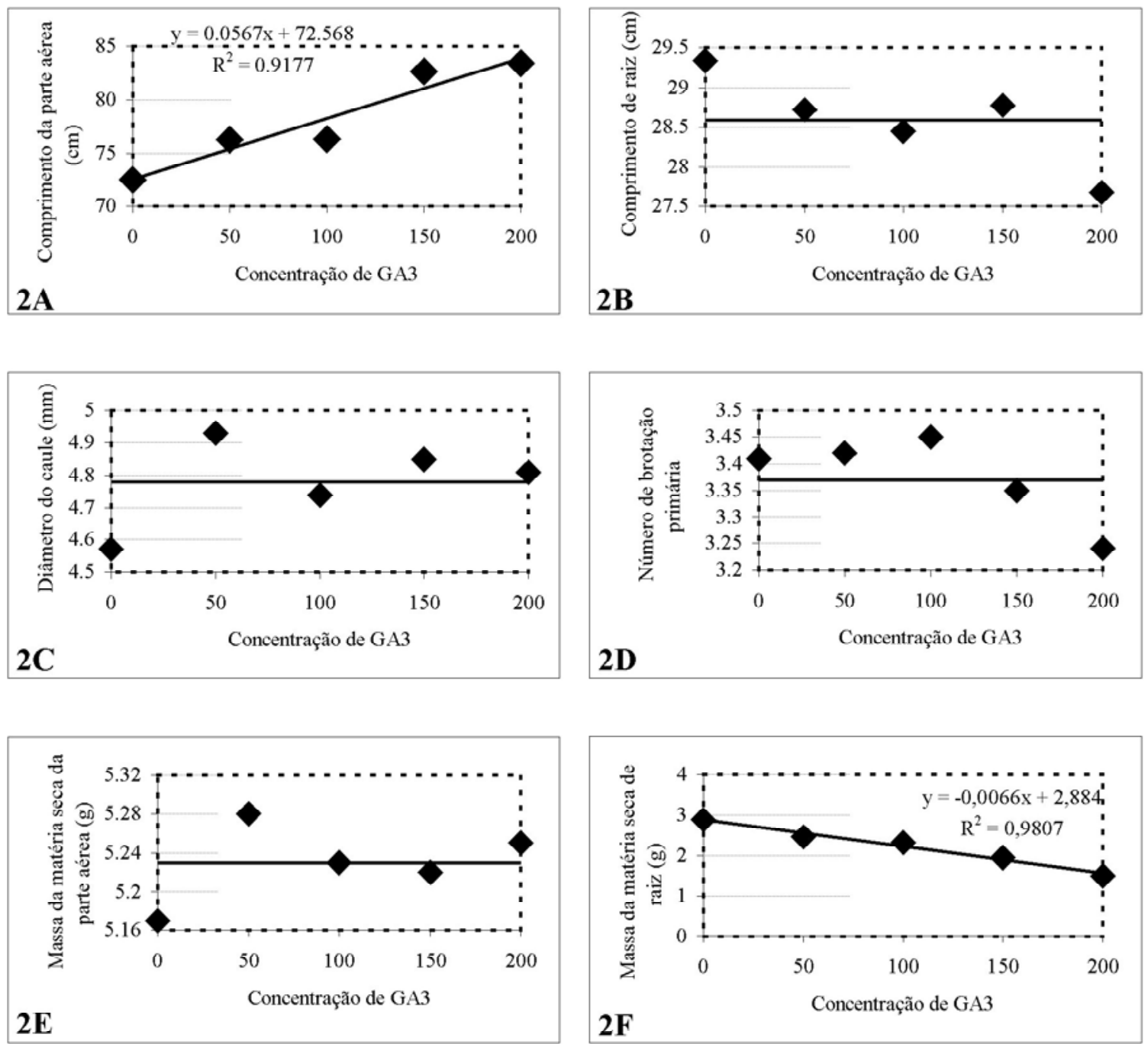

Figura 2 - Comprimento da parte aérea (A), e de raiz (B); diâmetro do caule (C); número de brotações primárias (D) e massa da matéria seca da parte aérea $(\mathrm{E})$ e de raiz $(\mathrm{F})$ do pessegueiro em cinco concentrações de $\mathrm{GA}_{3}\left(\mathrm{mg} \mathrm{L}^{-1}\right)$, aos 130 dias de cultivo.

No trabalho desenvolvido por Casper \& Taylor (1989), em plantas de pessegueiro, a pulverização de $50 \mathrm{mg} \mathrm{L}^{-1} \mathrm{de}$ $\mathrm{GA}_{3}$ proporcionou aumento no diâmetro dos ramos, bem como, no número de ramos laterais. No presente trabalho estes fatos não foram observados, uma vez que não houve efeito significativo da aplicação de $\mathrm{GA}_{3}$ sobre essas variáveis, mesmo utilizando maiores concentrações desse regulador de crescimento (Figuras $2 \mathrm{C}$ e $2 \mathrm{D}$ ).

De acordo com Schmidt et al. (2003), a ação de uma substância reguladora de crescimento depende de fatores ambientais, número e período de aplicação, concentração utilizada, estádio de crescimento da planta e da espécie ou cultivar tratada.
Nas condições em que foi realizado o presente trabalho, as pulverizações de $\mathrm{GA}_{3}$, em pessegueiro, tiveram efeito sobre o comprimento do caule, o qual pode ser fundamental para reduzir o período de produção de portaenxertos.

\section{CONCLUSÃO}

O ácido giberélico exerceu efeito sobre o crescimento de pessegueiro, recomendando-se a pulverização de $200 \mathrm{mg} \mathrm{L}^{-1}$.

As pulverizações de $\mathrm{GA}_{3}$ não tiveram efeito sobre o diâmetro do caule de pessegueiro. 


\section{REFERÊNCIAS BIBLIOGRÁFICAS}

AGRIANUAL. Anuário de agricultura brasileira. São Paulo: FNP Consultoria e Comércio, 2005.

ALVARENGA, A. Substâncias de crescimento vegetal e regulação do desenvolvimento vegetal. Lavras: UFLA, $1990.59 \mathrm{p}$.

CASPER, J. A.; TAYLOR, B. H. Growth and development of Young 'Loring'peach trees after foliar sprays of paclobutrazol and $\mathrm{GA}_{3}$. HortScience, Alexandria, v. 24, n. 2, p. 240-242, 1989.

CASTRO, P. R. C.; PENTEADO, S. R.; TERAMOTO, E. R. Promoção do desenvolvimento de nogueira macadâmia com reguladores vegetais visando a enxertia precoce. Anais Escola Superior de Agricultura "Luiz de Queiroz", Piracicaba, v. 48, p. 155-166, 1991.

COELHO, Y. S.; OLIVEIRA, A. A. R.; CALDAS, R. C. Efeitos do ácido giberélico $\left(\mathrm{GA}_{3}\right)$ no crescimento de porta-enxertos para citros. Pesquisa Agropecuária Brasileira, Brasília, v. 18, n. 11, p. 1229-1232, 1983.

LEONEL, S.; RODRIGUES, J. D. Efeito de fitorreguladores no crescimento e desenvolvimento do porta-enxerto de limoeiro 'Cravo'. In: CONGRESSO BRASILEIRO DE FISIOLOGIA VEGETAL, 5., 1995, Lavras. Resumos... Lavras: SBF, 1995. p. 19.

MARTH, P. C.; AUDIA, W. V.; MITCHELL, J. W. Effects of gibberellic acid on growth and development of plants of various genera and species. Botanical Gazette, Jstor, v. 118, p. 106-111, 1965.

MODESTO, J. C. Efeitos de diferentes reguladores de crescimento sobre o desenvolvimento de porta-enxerto de citros. 1994. 127 f. Dissertação (Mestrado em Fitotecnia) Faculdade de Ciências Agronômicas, Universidade Estadual Paulista, Botucatu, 1994.

MODESTO, J. C.; RODRIGUES, J. D.; PINHO, S. Z. Efeitos da aplicação de ácido giberélico $\left(\mathrm{GA}_{3}\right)$ em 'seedlings'de limão 'Cravo'(Citrus limonia Osbeck). In: REUNIÃO ANUAL DA SBPC, 46., 1994, Vitória. Anais... Vitória: UFES, 1994. p. 16.

MODESTO, J. C.; RODRIGUES, J. D.; PINHO, S. Z. Efeito do ácido giberélico sobre o comprimento e diâmetro do caule de plântulas de limão 'Cravo' (Citrus limonia Osbeck). Scientia Agrícola, Piracicaba, v. 53, n. 2/3, 1996.

PASQUAL, M.; CHALFUN, N. N. J.; RAMOS, J. D. Fruticultura comercial: propagação de plantas frutíferas. Lavras: UFLA/FAEPE, 2001. $137 \mathrm{p}$.

RAMOS, V. H. V. Efeitos do ácido giberélico e cycocel sobre porta-enxerto de mangueira (Mangifera indica $\mathrm{L}$.) em viveiro. 1980. 117 f. Dissertação (Mestrado em Fitotecnia) - Universidade Federal de Viçosa, Viçosa, 1980.

SAUTER, M.; KENDE, H. Gibberellin-induced growth and regulation of the cell division cycle in deepwater rice. Planta, Berlin, v. 188, p. 362-368, 1992.

SCHMIDT, C. M.; BELLÉ, R. A.; NARDI, C.; TOLEDO, K. A. Ácido giberélico $\left(\mathrm{GA}_{3}\right)$ no crisântemo (Dedranthema grandiflora Tzvelev.) de corte 'viking': cultivo de verão. Ciência Rural, Santa Maria, v. 33, n. 2, p. 267-274, 2003.

TAIZ, L.; ZEIGER, E. Fisiologia vegetal. 3. ed. Porto Alegre: Artmed, 2004. $719 \mathrm{p}$.

TING, I. P. The plant hormones. In: Plant physiology. Reading: Addison-Wesley, 1982. p. 481-508.

TOFANELLI, M. B. D.; CHALFUN, N. N. J.; HOFFMANN, A.; CHALFUN JÚNIOR, A. Uso do ácido indolbutírico na propagação de cultivares-copa de ameixa através de estacas lenhosas. Científica Rural, Bagé, v. 6, n. 1, p. 115-121, 2001.

ZONTA, E. P.; MACHADO, A. A. SANEST -Sistema de Análise Estatística para Microcomputadores. Pelotas: UFPel, 1984. $75 \mathrm{p}$. 